\title{
The Swedish National Diabetes Register in clinical practice and evaluation in primary health care
}

\author{
Ing-Marie Hallgren Elfgren ${ }^{1}$, Ewa Grodzinsky ${ }^{2}$ and Eva Törnvall ${ }^{3}$ \\ ${ }^{1}$ Social Scientist, R\&D Department of Local Care, Region Östergötland and Faculty of Medicine and Health Science, \\ Linköping University, Linköping, Sweden \\ ${ }^{2}$ Registered BLS, Associate Professor, Manager, Forensic Toxicology Laboratory, National Board of Forensic Medicine, \\ Faculty of Medicine and Health Science, Linköping University, Linköping, Sweden \\ ${ }^{3} R \& D$ Supervisor, R\&D Department of Local Care, Region Östergötland and Faculty of Medicine and Health Science, \\ Linköping University, Linköping, Sweden
}

\begin{abstract}
Aim: The purpose of this project is to describe the use of the Swedish National Diabetes Register (NDR) in clinical practice in a Swedish county and to specifically monitor the diabetes care routines at two separate primary health-care centres (PHCC) with a special focus on older patients. Background: According to Swedish law, all health-care units have to maintain a system for quality evaluation and improvement. As the NDR holds the most important quality indicators, implementation of the NDR in primary care was carried out by an implementation project in 2002-2005. Methods: Initially, a digital questionnaire about NDR routines was sent to all PHCC. Statistics about hemoglobin adult $1 \mathrm{c}(\mathrm{HbA} 1 \mathrm{c})$ and blood pressure $(\mathrm{BP})$ was presented for the diabetes teams at two centres who were also interviewed. The responses became the basis for a focus group interview with both teams together, with data subject to content analysis. Findings: The study showed that reporting to the NDR has become a compulsory routine in primary care. The diabetes nurse specialist was responsible for the practical management of the register and used the NDR for continuous monitoring of the patients. Most centres used the NDR's statistics for evaluation and analyses annually. The diabetes nurse adapted the visits to the patient's wishes and general condition. Only in terms of target values for $\mathrm{HbA} 1 \mathrm{c}$ and BP did they accept slightly higher values for the older patients. Since the NDR was implemented, the registration rate has remained at $75 \%$ and has not increased. The reason given was that patients with diabetes living in nursing homes are checked up by the municipal nurse who does not use the NDR. However, the risk of omitting older patients in the NDR could be considerably decreased if data could be transferred from the electronic patient record.
\end{abstract}

Key words: diabetes care; older patients; primary health care; quality register

Received 21 July 2015; revised 16 February 2016; accepted 4 March 2016;

first published online 4 April 2016

\section{National Quality Registers in the health service}

Quality of care has been defined in different ways, but the Donabedian model of structureprocess-result is still the dominant theoretical basis for describing and measuring quality in health care (Donabedian, 1966). Questions about the best outcome of care and treatments have resulted in definitions of quality indicators. In Sweden, quality indicators for the treatment and care of patients with different diagnoses have

Correspondence to: Ing-Marie Hallgren Elfgren, BA, R\&D Department of Local Care, Region Östergötland and Faculty of Medicine and Health Science, Linköping University, 58185 Linköping, Sweden. Email: hallgren.im@telia.com

(C) Cambridge University Press 2016 
been the basis for developing National Quality Registers, which have been recognized as very valuable for expanding databases by continuously reporting data from everyday clinical work. The purpose of the national registers is to provide medical care with data that show areas in need of improvement, present register data to enable the evaluation of improvement and use the data in research projects. In 2014, there were 81 Swedish Quality Registers, most of which provided data for use in somatic care in hospital (National Quality Registers, 2015).

Though primary health care (PHC) is still a field where only a few registers are applicable, the Swedish National Diabetes Register (NDR) maintains a lot of data from PHC and is one of the most comprehensive registers. Diabetes patients in specialist care, mainly type 1 and type 2 diabetes treated in PHC, are recorded in the NDR. In 2014, there were in total 330000 patients with type 2 diabetes registered in the NDR of which 320000 were treated and recorded in PHC (National Diabetes Register, 2014).

\section{Background}

According to the Wagner model (1998), the organization of health care in Sweden for most patients with chronic diseases is based on PHC, which is also the delivery level of most treatment, check-ups and self-management support. If needed, patients are occasionally referred to specialist care but $\mathrm{PHC}$ is responsible for the continuous monitoring.

The structure of the health-care organization in Sweden in general is as follows: there is a regional council in every county that receives tax revenue for funding primary health-care centres (PHCC), that is general practices and regional hospitals, although national laws and regulations have great influence over organization and activities (SFS, 1982:763). In addition to PHC and regional hospitals, there are several specialist clinics in the country that are organized and financed on national level. All inhabitants in Sweden make their own choice of PHCC. The patient pays a fee for each visit but there is an annual payment ceiling. When the patient reaches this upper limit, health care (specialist and primary care) is free for the rest of the year. There is a similar system concerning prescription medications. Patients with chronic diseases thus often have a so-called free pass for health care and medicines.

Children and most adult patients with type 1 diabetes receive specialist care, whereas almost all patients with type 2 diabetes - adult and older patients often with other chronic diseases or health problems - are treated and followed up at the PHCC. In the studied county there are 42 PHCCs. The staff consists of general practitioners (GP), diabetes nurse specialists (DNS), other nurses, dieticians and medical secretaries. There is also access to paramedical and laboratory personnel. The patients with diabetes are taken care of by a multi-professional team with the DNS and the GP responsible for diabetes care at the forefront of treatment (The Swedish National Board for Health and Welfare, 2015a). The DNS has a separate surgery that provides continuous monitoring of the patients with diabetes.

According to Swedish law, all health-care units have to maintain a system for quality evaluation and improvement (SOSFS, 2011:9). One such nationwide system is the National Quality Registers (Swedish Association of Local Authorities and Regions, 2013a). As the NDR contains the most important quality indicators (Eeg-Olofsson, 2010), the county council decided to implement the NDR at all PHCCs and set up an implementation project in the current county in 2002-2005 (Hallgren Elfgren et al., 2012). During the implementation phase there was ongoing financial support for recording patients in the NDR. This was withdrawn when the implementation project was completed in 2005. A follow-up in the early 2010s showed the registration rate was still as high as in 2005, and it also showed positive effects in medical outcomes (Hallgren Elfgren et al., 2013).

In Sweden, as in many countries, the older age group of the population is growing (SCB, 2014) and diabetes is increasingly common in older inhabitants. Globally, $15 \%$ of people over the age of 80 were estimated to have diabetes in the year 2000 (Wild et al., 2004). The National Board of Health and Welfare in Sweden has published guidelines for different diagnosis groups and also a special document that focusses on how the guidelines can be adapted to the most older patients who are ill. The fundamental principles are to adapt care to individual needs, to consider 
the relationship between benefit and risk, to define goals and to design the treatment thereafter (The Swedish National Board for Health and Welfare, 2015b).

\section{Aim}

The purpose of this project is to follow and describe the use of the NDR in clinical practice in a Swedish county, starting from the quality indicators in the NDR, to specifically monitor the diabetes care routines and activities at two separate PHCCs, with special focus on the older patients aged 75 years and over. The overall aim is, through continuous feedback from the ongoing study, by discussions and analysis in the diabetes teams, to provide incentives for improvements in clinical practice.

\section{Method}

A triangulation method was used in the study, incorporating the sequential data analysis of a questionnaire, statistics and interviews (Östlund et al., 2011). Initially, a digital questionnaire containing 15 questions, both fixed and open response options, mainly about local organization and routines, was sent to the diabetes teams at all 42 PHCCs in the county studied in 2012. As a second step, statistical extracts from the NDR concerning goal achievements for HbA1c $<73 \mathrm{mmol} / \mathrm{mol}$ (equivalent to $8 \%$ ) and mean values of blood pressure (BP) for diabetes patients aged 75-79 and 80 years and over were requested and analysed. The result of the statistical analysis was, together with the questionnaire responses, used for the construction of a guide for further interviews.

The sampling strategy for the interview was purposive to find diabetes teams that actively use the NDR, and have a special interest in the development of diabetes care. On the advice of the chairperson of the local diabetes council, which includes diabetes specialists of different professions and patient representatives, two PHCCs, named $A$ and $B$ in the present study, were invited to participate in the current project. The diabetes teams at the PHCC were interviewed separately using a semi-structured guide. The questions in the guide concerned the use of the NDR in clinical practice, registration rates, treatment strategies and target values for $\mathrm{HbA} 1 \mathrm{c}$ and $\mathrm{BP}$. There were also questions about variations and differences in goal achievements between the PHCCs. The results of the separate interviews became the basis for a focus group interview (Gibbs, 1997), where both teams met to express and compare their opinions and experiences, as well as discuss the statistics. Participants from the two PHCCs were, for A: the manager and two DNSs, for B: the manager, a GP (diabetes specialist) and two DNSs. One of the authors (E.T.) acted as an interview leader and one (I.-M.H.E.) as an observer.

\section{Analysis}

The statistics extracted from the NDR that concerned the achieved goals of registered patients were descriptively compiled with frequencies, means and proportions.

After the interviews were completed, the transcriptions underwent a direct topic by topic.

Both I.-M.H.E. and E.T. read through the whole text again to find key concepts for content analysis (Hsieh and Shannon, 2005). Two of the authors (E.T. and I.-M.H.E.) read and analysed all the text initial coding. The codes were then discussed, compiled and sorted by the main topics in the interviews:

- routines for diabetes care

- registration rate

- achievement of national goals for HbA1c and BP

- clinical use of the NDR.

For flowchart of the study see Figure 1.

\section{Demographic data of the participating PHCCs in 2012}

The two PHCCs participating in the interviews and focus group were as follows: A, located in a town with 150000 inhabitants, which had 19400 listed patients including 863 patients registered in the NDR; B, located in a town with 42000 inhabitants, which had 15140 listed patients including 594 patients registered in the NDR. 


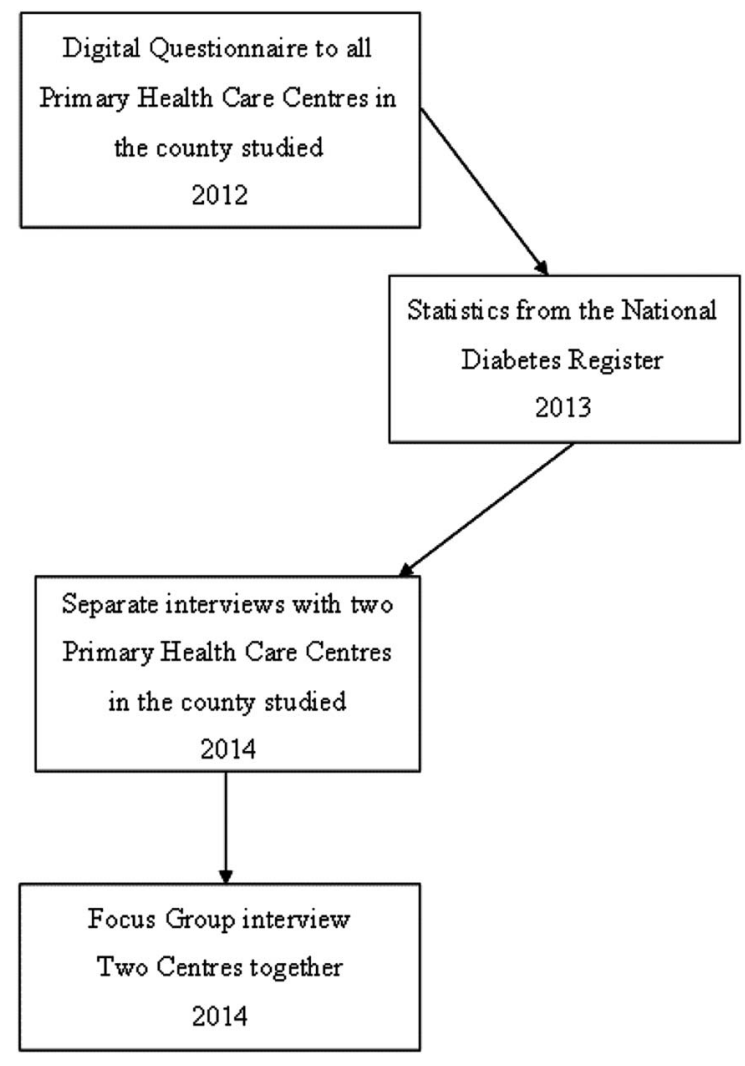

Figure 1 Flowchart of the study design

\section{Result}

\section{Digital questionnaire}

Complete answers to the digital questionnaire were sent from 72 individual respondents, together representing 36 of the 42 PHCCs in the county. The majority of the individual respondents stated that there was a specialist diabetes team at their PHCC and at the few remaining PHCCs there were most of the professionals that form part of a diabetes team, but not organized as a team. With scarcely any exceptions the registration in the NDR was carried out by the DNS, who also saw the patients for regular check-ups. Half of both GPs and DNSs answered that they used the NDR form at patient visits, but they wished there was an easier way to print out lists of test results (blood glucose, BP and so on) to give to the patient. As a comment, several respondents expressed that they lacked the ability to directly

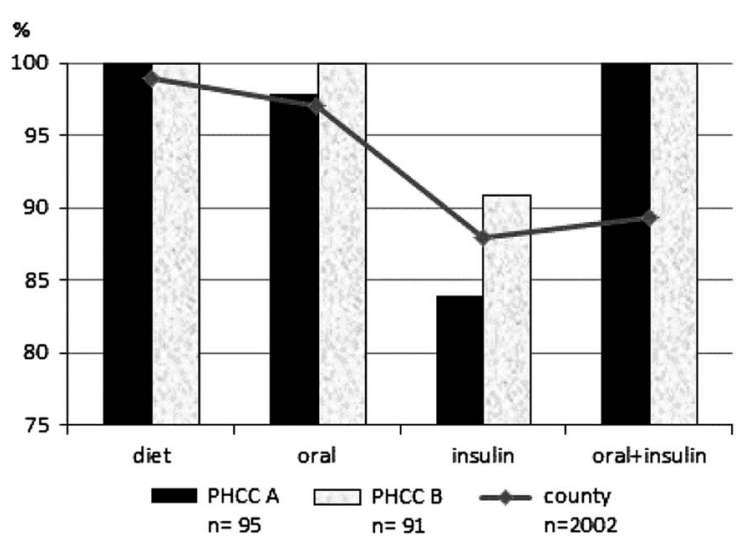

Figure 2 Goal achievement for $\mathrm{HbA} 1 \mathrm{c}<73 \mathrm{mmol} / \mathrm{mol}$. Patients with diabetes aged 75-79 years, registered in the Swedish National Diabetes Register in 2012. $\mathrm{PHCC}=$ Primary health care centres.

transfer data from the electronic medical record to the NDR.

The respondents also reported that statistics on an aggregate level were obtained from the NDR for presentations of results, evaluations and development discussions. A fifth, 21\% $(n=15)$, answered that this was done quarterly, $24 \%(n=17)$ at least once every half-year and $46 \%(n=33)$ at least once a year. Only 9\% $(n=7)$ of the respondents reported that they never extracted statistics from the NDR at their PHCC.

\section{Statistics from the NDR}

NDR statistics relating to the achievement of goals for $\mathrm{HbA} 1 \mathrm{c}$ were compiled for patients aged 75-79 and 80 years and over, and distributed after treatment. Results for the two current PHCCs and the county average are described in Figures 2 and 3.

The NDR statistics describing different treatment strategies for patients aged 80 years or over in the studied county are shown in Figure 4. The variables are presented as the number of patients.

The treatment group oral + insulin is relatively small and thus makes comparisons in terms of percentages uncertain.

Since the implementation of the NDR, primarily two quality indicators, $\mathrm{HbA} 1 \mathrm{c}$ and $\mathrm{BP}$, have been followed up annually and reported to the PHC managers and each PHCC. There has been 


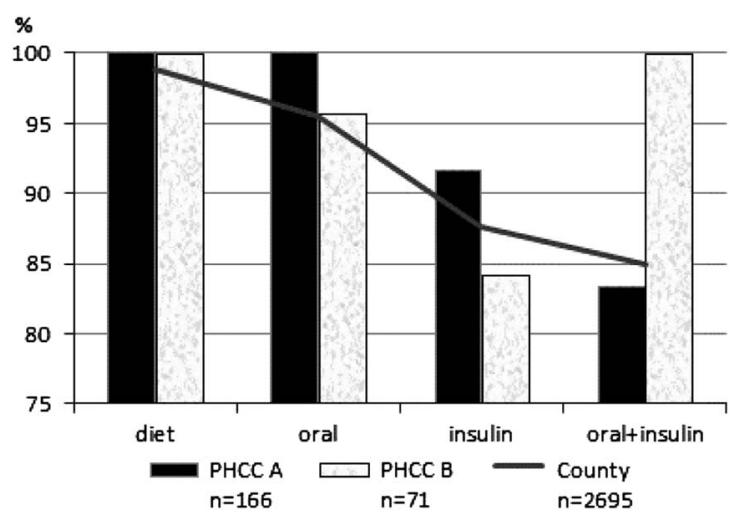

Figure 3 Goal achievement for $\mathrm{HbA} 1 \mathrm{c}<73 \mathrm{mmol} / \mathrm{mol}$. Patients with diabetes aged 80 years and over, registered in the Swedish National Diabetes Register 2012. $\mathrm{PHCC}=$ Primary health care centres.

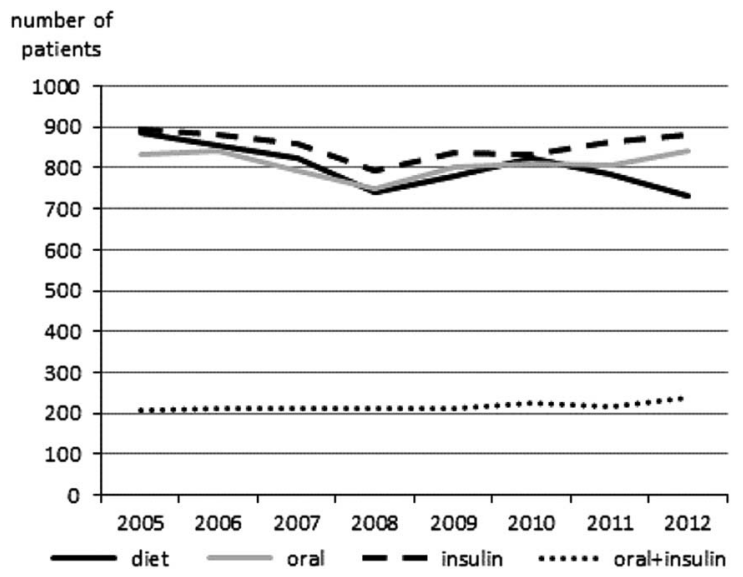

Figure 4 Treatment strategy groups in the studied county, current primary health care centres included. Patients with diabetes aged 80 years and over registered in the Swedish National Diabetes Register.

a steady downward trend in BP in the county, current PHCCs included, which can be seen in Figure 5.

\section{Interviews}

The presentation below is based on the two separate PHCCs interviews and the joint focus group interview. Compilation of the results is categorized on the basis of the question areas.

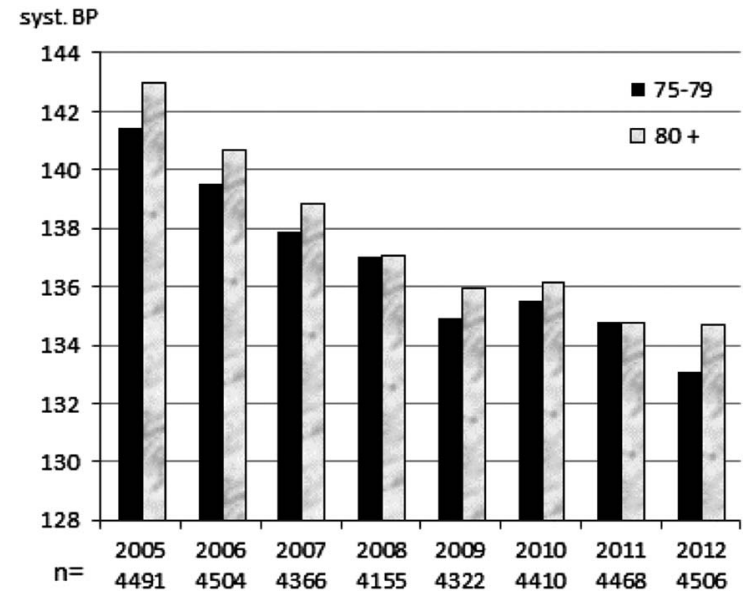

Figure 5 Mean values of systolic blood pressure (syst. BP) in the studied county (2005-2012). Patients with diabetes aged 75 years and over registered in the Swedish National Diabetes Register.

\section{Routines for diabetes care}

There were similar approaches to patients' diabetes check-ups at the two PHCCs and the DNS was responsible for the registration in the NDR. All newly diagnosed patients were called for an appointment with the nurse and, most often at the onset of diabetes, also offered an appointment with a dietician. The individual status and wishes of the patient were crucial for how the DNS arranged further visits. The age of the patient had no particular influence. Even if none of the DNSs followed the NDR entry form in the computer exactly during patient appointments, they all observed there had been better structure and clarity in patient meetings since the NDR was implemented. At both PHCCs the DNS saw the patients once a year, or more if needed, whereas the GP was only consulted or saw the patient for special needs. The GPs, however, had great confidence in the DNSs' skills and found that the patients received very good care by this practice:

'We of course call the patients for an appointment when they are diagnosed with diabetes and they come to see us regularly regardless of their age. An older patient who takes medication will maybe come more often. Older patients who undergo the right

Primary Health Care Research \& Development 2016; 17: 549-558 
treatment might come to us once a year. It depends on the individual. Age doesn't matter at all. It's what they do in life that counts. Some have insulin and handle everything just fine even though they are old'.

\section{(PHCC A)}

As part of the decision support, both teams followed national and local guidelines and they exchanged experiences in the focus group. National guidelines were considered to be too comprehensive for everyday clinical work. Therefore, a local version adapted to county conditions and derived from the national evidence-based guidelines, was embedded into daily clinical practice. One of the PHCCs had even developed its own local diabetes care programme, a sort of checklist adapted to the conditions of the individual centre:

'We have more definite target values and concise, easy to find target values and samples'.

(Focus group interview)

\section{Registration rate}

Since the implementation programme was completed, the registration rate in the county has remained at a level of $75 \%$ with only small deviations from one year to another. No single reason was mentioned as to why the NDR registration rate has stayed at $75 \%$, but there was a discussion about cooperation with the municipality concerning patients in nursing homes.

There were different communication routines between the PHCCs and the municipal nurses concerning data to be registered in the NDR. However, there was a common assumption that the main reason why some patients were not registered was that the municipal nurse did not report directly to the NDR. There was also a discussion about the interpretation of 'informed consent' for registration with regards to patients with dementia. Some interpretations proposed that consent need not be mandatory if the registration is not detrimental to the patient, whereas other interpretations asserted that at least a relative must give the consent. This legal uncertainty might result in some of the patients with dementia not being registered in the NDR. Other explanations as to why the registration rate did not increase were employee turnover, shortage of GPs and workload:

'Yes, it is the nursing home patients and without fail one or two don't come'.

(Focus group interview)

\section{Achievement of national goals for HbA1c and $B P$}

Treatment strategies in the older age group were mainly the same as in the other age groups, but at both PHCCs the team thought it might be better not to place too much pressure on the patients to achieve the goal levels for HbA1c or BP. The diabetes teams were willing to accept slightly higher values in the older age group if the influence of the treatment became negative for the patient's general condition. The current extract from the NDR goal value for HbA1c is $73 \mathrm{mmol} / \mathrm{mol}$; this target is acceptable for older patients in the local (county) guidelines.

Regarding goal values and the achievements of goals, individual considerations were very important as health varied greatly in the older age group. Some of the patients were quite healthy, whereas others might suffer from heart, cardiovascular or other diseases. At both interviews, the DNS and GP pointed out that special attention must be paid to renal dysfunction, which often is a result of long-term diabetes:

'You have to base your judgements very much on the symptoms. Older patients' values tend to be a little bit higher. There are other long-term blood sugar values for the really old'.

(Focus group interview)

'You must bear in mind that patients can get sick from something else, and then you have very small margins if you have pushed them too much'.

(Focus group interview)

\section{Clinical use of the NDR}

All the DNSs extracted statistics from the NDR as the basis for follow-up and evaluation of diabetes care at team, workplace and management meetings. Both teams confirmed that the manager showed great interest, which was important 
for the nurses' participation in the NDR registration. They saw there was significant value in comparisons but the DNSs' focus in daily clinical work was the individual diabetes patient. It therefore was important that the management showed an interest in the statistics, used them for followup, comparisons and development, and thereby encouraged the registration. Regardless of which PHCC, the participating DNSs felt that they had considerable responsibility for documenting a lot of information, and as diabetes care demands individual treatment they also had to build long-term relationships with most patients.

The project group did not take sufficient initiatives for comprehensive discussions about longterm development and incentives for improvements on the basis of the statistics. The DNSs saw that there was potential for development of diabetes care in the NDR. They were interested in correlations between different diagnoses and test values among the diabetes patients and knew that there were opportunities to cross-tabulate data in the NDR and make in-depth studies, but there was no time for this in their daily work so the discussions at the meetings were focussed on current quality indicators and daily clinical practice:

\begin{abstract}
'You can of course decide what you want to see. X picks out, for example, certain values that we look at together. Then together with the medical team we pick out values and discuss them with you, by all means. Precisely the clinical practice in the NDR'.
\end{abstract}

(PHCC B)

\section{Discussion}

The present study confirms that registration in the NDR has become a mandatory routine in diabetes care in PHC in the county studied. The NDR is used on an individual level at patient visits and as a tool for follow-up and evaluation at PHCC, county and national levels (The Swedish National Board for Health and Welfare, 2013).

In the focus group interview, the DNSs expressed that they felt they had a challenging role.

They had to learn every patient's individual circumstances and to build a long-term relationship with the patient. As has been shown by other studies, the DNS also plays an essential role in motivating patients to be an active participant in self-care (Bartol, 2012). The DNSs' professionalism was more pronounced in clinical practice than in the guidelines.

Although, for example, the guidelines recommend regular check-ups by the GP, the DNS instead saw the diabetes patients regularly and often more than once a year. The GP was consulted if there was something to discuss and saw the patient if needed. Both the GP and the DNSs thought their close cooperation ensured good care for the patient. Though this conduct deviated slightly from the national evidence-based guidelines, the latter were considered an important part of decision support (Wagner, 1998). However, the DNSs wanted more differentiated instructions and therefore appreciated the local version. Of course there is a risk of deviating from the guidelines if the implementation is done locally instead of systematically following a common structure with defined stages of implementation (Fixsen et al., 2005) in the whole county. The mandatory registration in the NDR has, however, made it possible to evaluate compliance to the guidelines in many respects (Swedish Association of Local Authorities and Regions, 2013b).

The teams expressed that individual status was more important than age when they evaluated the patient. However, age was taken into account when it concerned medical goals, for example, HbA1c and BP. The DNSs and GPs sometimes found it difficult to balance between national goals and the older patient's perceived health. On the one hand, it was important that the patient's general condition did not worsen due to an aggressive treatment strategy - on the other, it was known that the mortality risk from cardiovascular and ischaemic heart disease, as well as developing dementia, rose with increasing HbA1c (Gao et al., 2008; Matthew et al., 2010; Ramirez, 2014). In the goal achievements statistics, $\sim 100 \%$ for HbA1c in some of the treatment groups might seem surprising, but in the NDR statistics in this study the goal value for $\mathrm{HbA} 1 \mathrm{c}$ is $73 \mathrm{mmol} / \mathrm{mol}$. This is an optimal value for the older patient group stated in the local guidelines and takes into account the above discussion of balance. Among younger patients, the goal value in the NDR in general is $52-57 \mathrm{mmol} / \mathrm{mol}$. The insulin group receives the most aggressive treatment and does not have such a high achievement. Moreover, the statistics only describe the condition of patients registered in the NDR. 
In the discussion about treatment strategies, the group oral + insulin attracted a lot of attention.

Statistically it is a small group but it was not viewed as such by the diabetes teams. It could sometimes be difficult to achieve balance between oral medication and insulin injections, which might require more frequent visits and therefore could be perceived as time consuming.

It might also be the case that this treatment in many instances was more limited in time, that is the transition from oral to insulin treatment. As the statistics are based on annual registrations, there might be a large influx of patients in the current group and most of the individuals would be registered in the insulin group later on.

It is also well known that diabetes and hypertension cause a higher mortality risk (Campbell et al., 2009). In diabetes care in the county studied there has been a conscious and successful strategy to lower BP by medication and lifestyle changes. The interviewed diabetes teams could note that there had been a steady decrease in BP average ever since the implementation of the NDR. This was the case even among the older patients, which has been good so far, but the DNSs were a little worried that BP might continue to fall, which could worsen the patient's general condition and, for example, cause dizziness and falls. The diabetes teams were satisfied that the guidelines (The Swedish National Board for Health and Welfare, 2015a), now supported by other studies, had advocated a less aggressive hypertensive treatment and a slightly higher BP value (systolic $145 \mathrm{mmHg}$ ) for older diabetes patients (Zhao et al., 2013).

The registration rate has remained at $75 \%$ (county average), and has not increased since the completion of the implementation project in 2002-2005 (Hallgren Elfgren et al., 2012). The DNSs were responsible for registering patient data as well as extracting statistics, but they all lacked a technical solution for the transmission of data from the electronic patient journal to the NDR, which would facilitate the work. Workload and a shortage of GPs and DNSs might affect the registration activity, but the most common explanation for no increase was that patients in nursing homes are taken care of by the municipal nurse who does not register them in the NDR. Nevertheless, the current patients are listed at a PHCC and data should be reported back to the PHCC for further registration. Some of the older

Primary Health Care Research \& Development 2016; 17: 549-558 patients with diabetes also suffer from dementia and are not able to give their lawful consent to the registration. In the focus group, various interpretations of the law (SFS, 1998:04) were discussed and there is an ongoing national investigation into the ethical implications of this matter. It raises questions about integrity as well as the right for decision-incapable persons not to be deprived of the care to which they are entitled.

Nonetheless, the PHC provides health care for older patients with often more than one chronic disease in community settings. Studies have shown that improving outcomes in this population can be fraught with difficulty (Smith et al., 2012), but as diabetes is a substantial part of multi-morbidity it is of great interest to include these patients in the quality register.

Patients with diabetes in nursing homes, often frail individuals with high morbidity and special needs (Bravell, 2011), must be considered, but do not seem to be fully represented in the NDR. There is an obvious risk for systematic failure in the evaluation statistics if one group of patients is largely omitted.

\section{Conclusion}

Reporting to the NDR has become a compulsory routine in primary care in the county studied.

Both the questionnaire and the interviews confirm this, but work would be easier and the results more reliable if data could be transferred from the electronic patient record to the NDR.

Statistics from the NDR were used for follow-ups on individual as well as PHCC level and confirmed that there were good achievements of medical goals in the studied county.

The DNS had a central role in diabetes care in PHC and all patients were individually treated.

Only in terms of target values for HbA1c and BP was age taken in account. The DNSs saw there was potential for development and in-depth studies in the NDR, but there was no time for this in daily practice.

\section{Acknowledgement}

The authors wish to thank to the physicians, diabetes nurse specialists and primary health care centre executives who gave their time and shared their experiences. 


\section{References}

Bartol, T. 2012: Improving the treatment experience for patients with type 2 diabetes: role of the nurse practitioner. Journal of the American Academy of Nurse Practitioners 24, 270-76.

Bravell, M.E., Westerlind, B., Midlöv, P., Östgren, C.-J., Borgquist, L., Lannering, C. and Möllstad, S. 2011: How to assess frailty and the need for care? Report from the Study of Health and Drugs in the Elderly (SHADES) in community dwellings in Sweden. Archives of Gerontology and Geriatrics 53, 40-45.

Campbell, N.R.C., Leiter, L.A., Racholle, P., Tobe, S., Chockalingam, A., Ward, R., Morris, D. and Tsuyuki, R. 2009: Hypertension in diabetes: a call to action. Canadian Journal of Cardiology 25, 299-302.

Donabedian, A. 1966: Evaluating the quality of medical care. The Milbank Memorial Fund Quarterly 44, 166-206.

Eeg-Olofsson, K. 2010: Cardiovascular risk factors and complications in type 1and type 2 diabetes. Dissertation. University of Gothenburg, Gothenburg.

Fixsen, D.L., Naoom, S., Blasé, K., Friedman, R.M. and Wallace, F. 2005: Implementation research: a synthesis of the literature. Tampa, FL: University of South Florida, Louis de la Parte Florida Mental Health Institute, The National Implementation Research Network. Retrieved 27 November 2015 from http://cfs.cbcs.usf.edu/_docs/ publications/NIRN_Monograph_Full.pdf.

Gao, L., Matthews, F.E., Sargeant, L.A. and Brayne, C. 2008: An investigation of the population impact of variation in HbA1c levels in older people in England and Wales: from a population based multi-centre longitudinal study. BMC Public Health, doi: 10.1186/1471-2458-8-54.

Gibbs, A. 1997: Focus groups. Social Research UPDATE Issue 19. Retrieved 27 November 2015 from http://sru.soc.surrey. ac.uk/SRU19.html.

Hallgren Elfgren, I.-M., Grodzinsky, E. and Törnvall, E. 2013: Swedish Diabetes Register: a tool for quality development in primary health care. Primary Health Care Research \& Development 14, 250-57.

Hallgren Elfgren, I.-M., Törnvall, E. and Grodzinsky, E. 2012: The process of implementation of the diabetes register in primary health care. International Journal for Quality in Health Care 24, 419-24.

Hsieh, H.-F. and Shannon, S.E. 2005: Three approaches to qualitative content analysis. Quality Health Research 15, 1277-288.

Matthew, R.C., Ambrosius, W.T., Brillon, D.J., Buse, J.B., Byington, R.P., Cohen, R.M., Goff, D.C. Jr., Malozowski, S., Margolis, K.L., Probstfield, J.L., Schnall, A. and Seaquist, E.R. 2010: Epidemiologic relationships between A1C and all-cause mortality during a median 3-4 year follow-up of glycemic treatment in the ACCORD trial. Diabetes Care 33, 983-90.

National Diabetes Register. 2014: Swedish National Diabetes Register. Annual report. Retrieved 27 November 2015 from https:/www.ndr.nu/pdfs/Annual_Report_NDR_2013.pdf.
National Quality Registers. 2015: Nationella Kvalitetsregister (Quality Registres in Sweden). Retrieved 27 November 2015 from http://www.kvalitetsregister.se.

Östlund, A., Kidd, L., Wengström, Y. and Rowa-Dewar, N. 2011: Combining qualitative and quantitative research within mixed method research designs: a methodological review. International Journal of Nursing Studies 48, 369-83.

Ramirez, A., Wolfsgruber, S., Lange, C., Kaduszkiewicz, H., Weyrer, S., Werle, J., Pentzek, M., Fuchs, A., Riedel-Heller, S.G., Luck, T., Mösch, E., Bickel, H., Wiese, B., Prokein, J., König, H.-H., Brettschneider, C., Breteler, M.M., Maier, W., Jessen, F. and Scherer, M. 2014: Elevated $\mathrm{HbA} 1 \mathrm{c}$ is associated with increased risk of incident dementia in primary care patients. Journal of Alzheimer's Disease, doi: 10.3233/JAD-141521.

SCB (Statistiska Centralbyrån). 2014: Statistics Sweden. Retrieved 27 November 2015 from http://www.scb.se/.

SFS (Svensk Författningssamling; Swedish Statue Book). 1982:763. The Swedish law of health and welfare. Stockholm: The Swedish Parliament (in Swedish).

SFS (Svensk Författningssamling; Swedish Statue Book). 1998:04. The Personal Data Act. Stockholm: The Swedish Parliament (in Swedish).

Smith, S.M., Soubhi, H., Fortin, M., Hudson, C. and O'Dowd, T. 2012: Interventions for improving outcomes in patients with multimorbidity in primary care and community settings (review). The Cochrane Library. Issue 4. Retrieved 16 November 2015 from http://onlinelibrary.wiley.com/doi/ 10.1002/14651858.CD006560.pub2/abstract.

SOSFS (Socialstyrelsens författningsssamling; Swedish National Board of Health and Welfare Regulations and General Advices). 2011:9: Management system for systematic quality work. Administrative provisions and general advice from The Swedish Board for Health and Welfare (in Swedish). SOSFS Socialstyrelsens Föreskrifter och allmänna råd om ledningssystem för systematiskt arbete. Article 2011-6-38 (in Swedish).

Swedish Association of Local Authorities and Regions. 2013a: Quality registries in Sweden. Swedish Association of Local Authorities and Regions (in Swedish). Retrieved 27 November 2015 from http://www.kvalitetsregister.se/sekun darnavigering/inenglish.

Swedish Association of Local Authorities and Regions. 2013b: Success factors in diabetes care. A comparative study of diabetes care in primary care. The Swedish Association of Local Authorities and Regions (in Swedish). Sveriges Kommuner och Landsting. Framgångsfaktorer i diabetesvården. ISBN-nr: 978-91-7164-983-6.

The Swedish National Board for Health and Welfare. 2013: Quality and efficiency in Swedish health care - regional comparisons 2012. The Swedish National Board for Health and Welfare, Stockholm. Retrieved 27 November 2015 from http://www.socialstyrelsen.se/publikationer2013/2013-5-7.

The Swedish National Board for Health and Welfare. 2015a: National guidelines for diabetes care. The Swedish National Board for Health and Welfare (in Swedish), Stockholm. 
Retrieved 27 November 2015 from http://www.socialstyrelsen.se/nationellariktlinjerfordiabetesvard.

The Swedish National Board for Health and Welfare. 2015b: Most ill elderly and national guidelines. The Swedish National Board for Health and Welfare (in Swedish), Stockholm. Retrieved 27 November 2015 from http://www.socialstyrelsen.se/riktlinjer/ nationellariktlinjer/omnationellariktlinjer/mests jukaaldre.

Wagner, E.H. 1998: Chronic disease management: what will it take to improve care for chronic illness? Effective Clinical Practice 1, 2-4.
Wild, S., Roglic, G., Green, A., Sicree, R. and King, H. 2004: Global prevalence of diabetes: estimates for the year 2000 and projections for 2030. Diabetes Care 27, 1047-53.

Zhao, W., Katzmarzyk, P.T., Horswell, R., Wang, Y., Li, W., Johnson, J., Heymsfield, S.B., Cefalu, W.T., Ryan, D.H. and Hu, G. 2013: Aggressive blood pressure control increases coronary heart disease risk among diabetic patients. Diabetes Care 36, 3287-296. 